\title{
Exigência de treonina digestível para codornas de corte no período de 15 a 35 dias de idade
}

[Digestible threonine requirements for quail meat from 15 to 35 days of age]

\author{
A.P.S. Ton ${ }^{1}$, A.C. Furlan ${ }^{2}$, E.N. Martins ${ }^{2}$, E. Batista ${ }^{1}$, T. J. Pasquetti ${ }^{1}$, C. Scherer ${ }^{3}$, \\ T.C.O. Quadros ${ }^{4}$, M.P. Nonaka ${ }^{5}$ \\ ${ }^{1}$ Aluno de pós-graduação em Zootecnia - Universidade Estadual de Maringá, Maringá, PR \\ ${ }^{2}$ Universidade Estadual de Maringá - Maringá, PR \\ ${ }^{3}$ Aluno de pós-graduação - UNIOESTE - Marechal Cândido Rondon, PR \\ ${ }^{4}$ Aluno de pós-graduação - UNESP - Jaboticabal, SP \\ ${ }^{5}$ Zootecnista autônomo
}

\begin{abstract}
RESUMO
Estimou-se a exigência de treonina digestível ( $\mathrm{ThrD}$ ) para codornas de corte (Coturnix coturnix sp.) em fase de crescimento no período de 15 a 35 dias de idade. Foram utilizadas 1020 codornas com 15 dias de idade, não sexadas, distribuídas em um delineamento experimental inteiramente ao acaso, com seis porcentagens de adição de treonina digestível - 0,93; 1,00;1,07;1,14;1,21 e 1,28\% na dieta - , cinco repetições e 34 codornas por unidade experimental. Não houve efeito sobre o desempenho, o rendimento e a composição química da carcaça e sobre o balanço de nitrogênio com o aumento da porcentagem de treonina digestível na dieta. Houve aumento linear no consumo de treonina e no custo da ração por quilograma de peso vivo ganho com o aumento da porcentagem de treonina digestível. Concluiu-se que o melhor nível de treonina digestível avaliado foi suficiente para atender as exigências de codornas de corte, no período de 15 a 35 dias de idade.
\end{abstract}

Palavras-chave: aminoácidos sintéticos, balanço de nitrogênio, codornas, composição corporal, desempenho, rendimento de carcaça

\begin{abstract}
The digestible threonine (DThr) requirements for meat quails (Coturnix coturnix sp) during growing phase from 15 to 35 days of age were estimated, using 1,020 quails with 15 days of age, of both sexes, distributed in a completely randomized design, with six levels of digestible threonine - 0.93; 1.00; 1.07; $1.14 ; 1.21$ and $1.28 \%$ in diet, five replications and 34 quails per experimental unit. There was no effect on performance variables, carcass yield and chemical composition and nitrogen balance with the studied increase in digestible threonine levels. There was a linear increase in threonine intake and feed cost per kilogram of body weight gain with increasing levels of digestible threonine. It was concluded that the best level of threonine evaluated was sufficient to meet the requirements of meat quails, in the period from 15 to 35 .
\end{abstract}

Keywords: body composition, carcass yield, quail, nitrogen balance, performance, synthetic aminoacids

\section{INTRODUÇÃO}

A criação de codornas para produção de carne é uma boa alternativa para obtenção de proteína de origem animal, pois suas instalações não necessitam de grandes investimentos, uma vez que este animal é pequeno, ocupa pouco espaço e sua produção de dejetos é inferior à das criações de animais convencionais (Móri et al., 2005). Devido ao fato de a carne apresentar características sensoriais de grande aceitabilidade pelo consumidor, considerada exótica, e ser

Recebido em 8 de julho de 2011 
reconhecida por sua alta qualidade e palatabilidade, a criação de codornas tem despertado interesse de empresas avícolas para exploração comercial (Oliveira et al., 2005).

Em vários países, a preocupação com a questão ambiental impôs novo desafio aos nutricionistas e novo fôlego às pesquisas. A eficiência de utilização da proteína da dieta pelos animais é baixa, levando, como consequência, a uma grande excreção de nitrogênio nas fezes. Esse excesso pode ser reduzido por meio do fornecimento de rações mais eficientes, com redução no teor de proteína (Fraiha, 2002). A disponibilidade econômica dos aminoácidos industriais lisina, metionina, treonina $\mathrm{e}$ triptofano para aves e suínos, assim como a melhor avaliação dos ingredientes e dos requisitos nutricionais, permite aos nutricionistas formularem rações com menores níveis proteicos (Moura, 2004). A treonina é o terceiro aminoácido limitante para aves, precedido da metionina e da lisina, sendo o mais importante, sobretudo, nas fases mais avançadas do desenvolvimento da ave, porque a proporção de exigência de treonina para mantença é alta em relação aos demais aminoácidos em razão de seu grande conteúdo nas secreções intestinais endógenas (Fernandez et al., 1994). Segundo Corzo et al. (2007), mais da metade da treonina consumida é utilizada nos intestinos para as funções de mantença, sendo primariamente utilizada na síntese de mucina.

Apesar do crescente e recente interesse na atividade, ainda são escassas as pesquisas sobre exigências nutricionais que alicerçam a formulação de dietas de mínimo custo ou de máximo retorno para codornas de corte em fase de crescimento. Portanto, o presente trabalho teve como objetivo estimar a melhor porcentagem de inclusão de treonina digestível para o máximo desempenho, rendimento e composição química da carcaça, a menor excreção de nitrogênio e a análise econômica da ração de codornas de corte (Coturnix coturnix sp.) em crescimento de 15 a 35 dias de idade.

\section{MATERIAL E MÉTODOS}

O experimento foi realizado com 1020 codornas de corte, não sexadas, com 15 dias de idade e média de peso de $77,11 \mathrm{~g} \pm 0,88$. As aves foram distribuídas em um delineamento inteiramente ao acaso com seis porcentagens de treonina digestível, cinco repetições e 34 aves por unidade experimental. Aos 15 dias de idade, as aves foram pesadas e distribuídas conforme descrito por Sakomura e Rostagno (2007), buscando uniformizar as unidades experimentais. Ao final do experimento, foram realizadas a contagem das aves e a determinação da proporção macho e fêmea em cada unidade experimental. As aves foram alojadas em um galpão convencional, coberto com telha de fibra amianto e dividido em 30 boxes com $2,5 \mathrm{~m}^{2}$ telados e com piso de terra batida, sendo utilizada casca de arroz como cama. O programa de iluminação utilizado foi de 24 horas por dia (natural + artificial) durante todo o período experimental.

As temperaturas máxima e mínima foram monitoradas durante todo o período experimental, sendo seus valores registrados às oito e às 16 horas, utilizando-se para este fim um termômetro de bulbo seco. As temperaturas máxima e mínima médias foram, respectivamente: 35 e $23^{\circ} \mathrm{C}$ no período da manhã e 34 e $24^{\circ} \mathrm{C}$ no período da tarde.

As dietas experimentais consistiram de seis porcentagens de inclusão de treonina digestível 0,$93 ; 1,00 ; 1,07 ; 1,14 ; 1,21$ e $1,28 \% \quad-$, isoproteicas, isoenergéticas, isocálcicas e isofosfóricas, formuladas à base de milho e farelo de soja (Tab. 1). A composição química e os valores energéticos dos alimentos foram os obtidos de Rostagno et al. (2005). Para atender às exigências nutricionais, adotaram-se as recomendações preconizadas por Scherer (2009) para lisina digestível e energia metabolizável e por Silva et al. (2009) para cálcio e fósforo disponíveis das dietas.

Os teores de metionina+cistina e triptofano digestíveis das dietas foram calculados de acordo com a relação proposta por Rostagno et al. (2005) para frangos de corte na fase inicial de um a 21 dias de idade, correspondendo à relação de lisina digestível:metionina+cistina e triptofano digestíveis de 72 e 17, respectivamente. Todas as dietas foram suplementadas com aminoácidos sintéticos em quantidades suficientes para se obter as relações desejadas entre os aminoácidos. 
Exigência de treonina...

Tabela 1. Composição percentual e nutricional das rações experimentais para codornas de corte em crescimento ( 15 a 35 dias de idade)

\begin{tabular}{lcccccc} 
Variável & \multicolumn{7}{c}{ Treonina digestível (\%) } \\
\cline { 2 - 7 } & 0,93 & 1,00 & 1,07 & 1,14 & 1,21 & 1,28 \\
\hline Milho grão & 65,928 & 66,062 & 66,199 & 66,334 & 66,470 & 66,605 \\
Farelo de soja (45\%) & 28,283 & 28,096 & 27,910 & 27,722 & 27,539 & 27,353 \\
Óleo de soja & 0,822 & 0,787 & 0,751 & 0,716 & 0,683 & 0,647 \\
Fosfato bicálcico & 1,658 & 1,658 & 1,658 & 1,658 & 1,658 & 1,658 \\
Calcário & 0,304 & 0,304 & 0,304 & 0,304 & 0,304 & 0,304 \\
L-Lisina HCL (78\%) & 1,150 & 1,155 & 1,160 & 1,166 & 1,172 & 1,177 \\
DL-Metionina (98\%) & 0,726 & 0,728 & 0,728 & 0,730 & 0,731 & 0,733 \\
L-Treonina (98\%) & 0,340 & 0,420 & 0,499 & 0,578 & 0,650 & 0,729 \\
L-Triptofano (98\%) & 0,088 & 0,089 & 0,090 & 0,091 & 0,092 & 0,093 \\
Sal comum & 0,391 & 0,391 & 0,391 & 0,391 & 0,391 & 0,391 \\
Suplemento mineral/vitamínico & 0,300 & 0,300 & 0,300 & 0,300 & 0,300 & 0,300 \\
Antioxidante ${ }^{2}$ & 0,010 & 0,010 & 0,010 & 0,010 & 0,010 & 0,010 \\
\hline Total & 100,00 & 100,00 & 100,00 & 100,00 & 100,00 & 100,00 \\
\hline & Composição nutricional calculada & & & \\
\hline Proteína bruta (\%) & 20,00 & 20,00 & 20,00 & 20,00 & 20,00 & 20,00 \\
Energia metab. (kcal/kg) & 3.036 & 3.036 & 3.036 & 3.036 & 3.036 & 3.036 \\
Cálcio (\%) & 0,61 & 0,61 & 0,61 & 0,61 & 0,61 & 0,61 \\
Fósforo disponível (\%) & 0,41 & 0,41 & 0,41 & 0,41 & 0,41 & 0,41 \\
Lisina digestível (\%) & 1,73 & 1,73 & 1,73 & 1,73 & 1,73 & 1,73 \\
Metionina+cistina digest. (\%) & 1,24 & 1,24 & 1,24 & 1,24 & 1,24 & 1,24 \\
Treonina digestível (\%) & 0,93 & 1,00 & 1,07 & 1,14 & 1,21 & 1,28 \\
Triptofano digestível (\%) & 0,28 & 0,28 & 0,28 & 0,28 & 0,28 & 0,28 \\
\hline Suplanyyyyyyyyyyyy
\end{tabular}

${ }^{1}$ Suplementação vitamínica/mineral (níveis de garantia por kg do produto); vit. A - 4.500.000UI; vit. D3 - 1.250.000

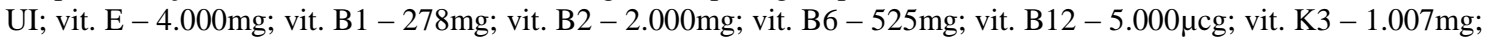
pantotenato de cálcio - 4.000mg; niacina - 10.000mg; colina - 140.000mg; antioxidante - 5.000mg; zinco $31.500 \mathrm{mg}$; ferro $-24.500 \mathrm{mg}$; manganês $-38.750 \mathrm{mg}$; cobre $-7.656 \mathrm{mg}$; cobalto $-100 \mathrm{mg}$; 5 odo $-484 \mathrm{mg}$; selênio $127 \mathrm{mg}$.

${ }^{2}$ BHT(Butil-hidroxitolueno).

As codornas foram pesadas semanalmente, e simultaneamente foram realizadas as pesagens das rações experimentais fornecidas, para a determinação do consumo de ração (g/ave), do consumo de treonina (g/ave), do ganho de peso (g), do peso corporal (g) e da conversão alimentar (g/g).

Para a determinação do rendimento de carcaça, aos 35 dias de idade, foram utilizadas quatro codornas - dois machos e duas fêmeas -, por unidade experimental, selecionadas pelo peso médio $( \pm 10 \%)$ de cada unidade experimental 20 codornas por tratamento -, as quais foram submetidas a quatro horas de jejum, sendo sacrificadas por decapitação entre os ossos occipital e atlas, feita com tesoura. As aves foram sangradas por dois minutos em cone adaptado para codornas e escaldadas por 20 a 40 segundos à temperatura de $53-55^{\circ} \mathrm{C}$. A depena foi manual e as aves foram evisceradas por meio de corte abdominal. Para o cálculo de rendimento de carcaça, foi considerado o peso da carcaça eviscerada, sem os pés e a cabeça, em relação ao peso vivo, o qual foi obtido individualmente antes do abate das aves. Para o rendimento de cortes, foi considerado o rendimento de peito e pernas (coxa e sobrecoxa) com pele e osso, sendo calculado em relação ao peso da carcaça eviscerada.

O estudo da composição química da carcaça foi realizado por meio do abate referencial feito a partir de um grupo adicional de seis codornas três machos e três fêmeas com peso médio de $78,21 \mathrm{~g} \pm 2,18$ com 15 dias de idade depenadas e evisceradas, comparadas com as codornas abatidas ao término do período experimental. Para o estudo da composição química da carcaça, foram considerados os cortes nobres - peito e pernas - obtidos durante o rendimento de carcaça. Os cortes nobres foram congelados em 
sacos plásticos devidamente identificados por tratamento e repetição e, posteriormente, foram moídos em moinho de carne industrial.

Os cortes moídos foram pesados, homogeneizados e levados à estufa de ventilação forçada a $55^{\circ} \mathrm{C}$ por 72 horas, para a realização da pré-secagem. Após a pré-secagem, os cortes foram moídos em moinho tipo martelo e encaminhados para as determinações analíticas em laboratório de nutrição e alimentação animal.

Foram determinados: matéria seca, umidade, proteína bruta, extrato etéreo e cinzas das carcaças, conforme metodologias descritas por Silva e Queiroz (2004), e calculadas as taxas de deposição de proteína $(\mathrm{TDP}=(\mathrm{QPcf}-$ $\mathrm{QPci}) / \mathrm{PE})$, de gordura na carcaça $(\mathrm{TDG}=(\mathrm{QGcf}$ - QGci)/PE) e de energia retida na carcaça (ERC $=5,66 \mathrm{TDP}+9,37 \mathrm{TDG})$, conforme metodologias descritas por Fraga et al. (2008).

No período de 28 a 35 dias de idade, foi realizado um ensaio para determinação do balanço de nitrogênio, em que foram utilizados 150 machos - 25 codornas/tratamento -, com 28 dias de idade, os quais foram retirados das respectivas unidades experimentais do experimento de desempenho e alojados em gaiolas de arame galvanizado, com bebedouro tipo nipple, comedouro individual tipo calha e bandeja metálica individual, forrada com plástico, para coleta das excretas.

O delineamento experimental utilizado foi inteiramente ao acaso, em que as porcentagens de inclusão de treonina digestível utilizadas foram as mesmas do experimento de desempenho, totalizando seis porcentagem de treonina digestível, com cinco repetições e cinco aves por unidade experimental. As dietas experimentais foram pesadas no início e no final do ensaio de balanço de nitrogênio, sendo utilizado o óxido férrico $(2 \%)$ na ração como marcador do início e do final do período de coleta das excretas. O período de coleta foi de cinco dias, sendo as excretas coletadas no período da manhã. Após cada coleta, as excretas foram acondicionadas em sacos plásticos, devidamente identificadas por tratamento e repetição e armazenadas em congelador. Ao final do período experimental, as excretas foram descongeladas, homogeneizadas, pesadas e mantidas em estufa de ventilação forçada a $55^{\circ} \mathrm{C}$ por 72 horas, para realização da pré-secagem. Após a pré-secagem, foram moídas em moinho tipo martelo e encaminhadas para a quantificação do teor de nitrogênio. Os teores de nitrogênio das dietas e das excretas foram obtidos pelo método de Kjeldahl, de acordo com Silva e Queiroz (2004).

Foi calculado o balanço de nitrogênio (g/dia) pela diferença entre o consumo de nitrogênio e a excreção de nitrogênio e o coeficiente de metabolizabilidade (\%) do nitrogênio das dietas experimentais.

Foi realizada a análise econômica das rações determinando-se o custo de ração por quilograma de peso vivo ganho (Yi), segundo Bellaver et al. (1985).

Para a análise estatística dos dados, utilizou-se o SAEG (Sistema..., 1997). Os graus de liberdade referentes à inclusão de treonina digestível foram desdobrados em polinômios. A estimativa de exigência de treonina digestível foi obtida aplicando-se o modelo quadrático.

\section{RESULTADOS E DISCUSSÃO}

A inclusão de treonina digestível às dietas não influenciou $(\mathrm{P}>0,05)$ o consumo de ração $(\mathrm{CR})$, o ganho de peso (GP), o peso corporal (PC) e a conversão alimentar (CA) no período de 15 a 35 dias de idade (Tab. 2). Resultados semelhantes foram obtidos por Baylan et al. (2006), que não observaram efeito dos diferentes níveis de treonina total $(0,81$ a $1,06 \%)$ para o desempenho de codornas japonesas no período de um a 35 dias de idade. Da mesma forma, Berres et al. (2007), ao avaliarem respostas de frangos de corte de 15 a 37 dias de idade, com aumentos graduais na relação lisina:treonina, também não verificaram efeito para as variáveis de desempenho estudadas com o aumento dos níveis de treonina digestível na ração.

Nobre et al. (2009), ao estudarem o desempenho de codornas japonesas no período de 22 a 42 dias de idade, alimentadas com diferentes porcentagens de treonina digestível na dieta (0,86 a $1,18 \%)$, verificaram efeito quadrático sobre ganho de peso e consumo de ração. Os melhores desempenhos foram obtidos com a inclusão de $1,02 \%$ de treonina digestível, 
diferentemente dos resultados observados no presente trabalho.

$\mathrm{O}$ aumento de treonina digestível promoveu aumento linear $(\mathrm{P}<0,05)$ no consumo de treonina (CT), que variou de 4,19 a $5,69 \mathrm{~g} /$ ave. De acordo com a equação de regressão $\mathrm{CT}=-0,505505+$ $4,54215 \mathrm{ThrD}$, para cada $1 \%$ de treonina digestível a mais na dieta, houve aumento no CT de 4,54g/ave no período de 15 a 35 dias de idade. A variação observada no $\mathrm{CT}$, em razão do aumento da concentração de treonina na dieta, pode ser justificada pelo fato de o consumo de ração não ter variado entre os tratamentos. Portanto, a menor porcentagem de treonina digestível estudada, $0,93 \%$, foi suficiente para satisfazer as necessidades das codornas, sem comprometer o desempenho.

Deve-se levar em consideração que, apesar de os resultados de consumo de ração não terem apresentado efeito $(\mathrm{P}>0,05)$, os valores estão próximos aos dados obtidos por Albino e Barreto (2003), que citaram consumo médio diário de ração por ave entre 23 e $26 \mathrm{~g}$, para codornas japonesas na fase adulta.

Tabela 2. Valores médios de desempenho, rendimento de carcaça e custo de ração de codornas de corte no período de 15 a 35 dias de idade em função da porcentagem de treonina digestível

\begin{tabular}{|c|c|c|c|c|c|c|c|c|}
\hline \multirow[t]{2}{*}{ Variável } & \multicolumn{6}{|c|}{ Treonina digestível (\%) } & \multirow[t]{2}{*}{$\mathrm{CV}$} & \multirow[t]{2}{*}{ Efeito $^{1}$} \\
\hline & 0,93 & 1,00 & 1,07 & 1,14 & 1,21 & 1,28 & & \\
\hline Consumo de ração (g/ave) & 449,98 & 452,14 & 444,94 & 448,12 & 454,24 & 448,02 & 2,852 & NS \\
\hline $\begin{array}{l}\text { Consumo de treonina } \\
\text { (g/ave) }\end{array}$ & 4,19 & 4,52 & 4,76 & 5,06 & 5,45 & 5,69 & 2,962 & Linear \\
\hline Ganho de peso (g) & 141,12 & 142,51 & 140,68 & 139,81 & 141,01 & 140,06 & 2,321 & NS \\
\hline Peso corporal aos $35 \mathrm{~d}(\mathrm{~g})$ & 218,19 & 219,91 & 217,25 & 216,88 & 217,80 & 217,53 & 1,378 & NS \\
\hline Conversão alimentar $(\mathrm{g} / \mathrm{g})$ & 3,19 & 3,17 & 3,16 & 3,21 & 3,22 & 3,20 & 2,624 & NS \\
\hline $\begin{array}{l}\text { Rendimento de carcaça } \\
(\%)\end{array}$ & 69,43 & 69,93 & 69,13 & 69,69 & 68,48 & 70,14 & 2,433 & NS \\
\hline Rendimento de peito $(\%)$ & 43,76 & 43,56 & 44,08 & 44,15 & 43,65 & 44,44 & 3,412 & NS \\
\hline Rendimento de pernas (\%) & 23,98 & 25,17 & 25,85 & 26,79 & 26,29 & 25,36 & 10,752 & NS \\
\hline Custo (R $\$ / k g$ PV ganho) & 2,55 & 2,57 & 2,60 & 2,67 & 2,72 & 2,74 & 2,565 & Linear \\
\hline
\end{tabular}

Equação de regressão

$\mathrm{CT}=-0,505505+4,54215 \mathrm{ThrD} ; \mathrm{R}^{2} 1,00$

Custo $=1,95487+0,625095 \mathrm{ThrD} ; \mathrm{R}^{2} 0,97$

${ }^{1}$ Análise de regressão; NS - não significativo; CT - consumo de treonina.

Em trabalho realizado com frangos de corte de 24 a 38 dias de idade, alimentados com diferentes níveis de treonina digestível na dieta $(0,565$ a $0,715 \%)$, Atêncio et al. (2004) não observaram efeito sobre qualquer característica de desempenho avaliada, exceto o aumento linear no consumo de treonina. Os autores concluíram que o nível de $0,637 \%$ de treonina digestível, correspondente à relação lisina:treonina digestível de 60, foi suficiente para atender a exigência das aves para o máximo desempenho. De acordo com Rostagno et al. (2005), frangos de corte machos de desempenho regular apresentam exigências de treonina digestível de 0,72 e $0,68 \%$ no período de oito a 21 e 22 a 33 dias de idade. As codornas de corte podem ser favoravelmente comparadas com os frangos de corte em relação ao seu desempenho e ao acelerado crescimento.
Embora os resultados obtidos não tenham apresentado efeitos significativos, a exigência para codornas de corte deste trabalho foi de $0,93 \%$ de treonina digestível. Cabe salientar que a exigência mínima para o máximo desempenho poderia estar abaixo desse menor nível estudado, podendo estar mais próxima da exigência de frangos de corte. Outro fator que pode ter influenciado tais resultados é que, de acordo com Kidd e Kerr (1996), o conceito de proteína ideal pode minimizar a variabilidade das exigências em treonina, como também em outros aminoácidos essenciais, por meio da utilização de relações aminoácidos essenciais:lisina específicas. No presente trabalho, foi mantida a relação lisina digestível:metionina+cistina e triptofano digestível proposta por Rostagno et al. (2005) para frangos de corte na fase de um a 21 dias de idade. Contudo, essas relações podem não ser adequadas para codornas de corte, 
o que sugere diferenças nas necessidades aminoacídicas entre essas espécies.

Os rendimentos de carcaça e de cortes nobres (peito e pernas) não foram influenciados $(\mathrm{P}>0,05)$ pelos níveis de treonina digestível nas rações (Tab. 2). Resultados semelhantes foram observados por Baylan et al. (2006), os quais não constataram diferença quando avaliaram o rendimento de carcaça de codornas japonesas aos 35 dias de idade, alimentadas com diferentes níveis de treonina total $(0,81$ a $1,06 \%)$. Corzo et al. (2007), ao avaliarem o rendimento de carcaça em frangos de corte aos 42 dias de idade, alimentados com porcentagens crescentes de treonina total $(0,51$ a $0,86 \%)$, verificaram efeito quadrático para peso de carcaça, com melhor estimativa de $0,72 \%$ de treonina total.

O aumento da porcentagem de treonina digestível na dieta promoveu aumento linear $(\mathrm{P}<0,05)$ do custo da ração por quilograma de peso vivo ganho (Tab. 2). Com o aumento dos aminoacídicos, houve maior inclusão de aminoácidos sintéticos, o que onerou o custo das rações. De acordo com a equação de regressão custo $=1,95487+0,625095 \mathrm{ThrD}$, para cada $1 \%$ de treonina digestível a mais na ração, houve aumento no custo da ração de $0,63 \mathrm{R} \$ / \mathrm{kg}$ de peso vivo ganho.

Segundo Fisher (1994), os efeitos do incremento progressivo dos aminoácidos dietéticos nas aves seguem uma hierarquia, a saber: exigência para máximo crescimento, exigência para melhor conversão alimentar, exigência para melhor carcaça com menos gordura, exigência para ótima composição de carcaça e exigência para maior peito. Observa-se, neste experimento, que o menor nível de treonina digestível $(0,93 \%)$ avaliado foi suficiente para promover o máximo desempenho das aves.

Os teores de água, proteína bruta, gordura, cinzas, a taxa de deposição de proteína (TDP) e gordura (TDG) na carcaça e a energia retida na carcaça (ERC) de codornas de corte não foram influenciados $(\mathrm{P}>0,05)$ pela inclusão de treonina digestível (Tab. 3). Esses resultados estão de acordo com Soares et al. (1999), que não evidenciaram diferença na composição corporal de frangos de corte aos 42 dias de idade com o aumento dos níveis de treonina digestível $(0,67$ a 0,87\%). Reginatto et al. (2000), ao avaliarem a suplementação de treonina em dietas de frangos de corte de 22 a 40 dias de idade, variando a energia e as relações energia:proteína, não observaram efeito sobre a composição da carcaça de frangos de corte em função da porcentagem de treonina digestível na dieta.

O balanço de nitrogênio (BN) e o coeficiente de metabolizabilidade do nitrogênio (CM) não apresentaram efeito $(\mathrm{P}>0,05)$ em função dos níveis de treonina digestível (Tab. 4).

Tabela 3. Valores médios da composição química da carcaça (CQC), taxa de deposição de proteína (TDP), taxa de deposição de gordura (TDG) e energia retida na carcaça (ERC) de codornas de corte aos 35 dias de idade em função da porcentagem de inclusão de treonina digestível

\begin{tabular}{|c|c|c|c|c|c|c|c|c|}
\hline \multirow[t]{2}{*}{ Variável } & \multicolumn{6}{|c|}{ Treonina digestível (\%) } & \multirow[t]{2}{*}{$\mathrm{CV}$} & \multirow[t]{2}{*}{ Efeito $^{T}$} \\
\hline & 0,93 & 1,00 & 1,07 & 1,14 & 1,21 & 1,28 & & \\
\hline \multicolumn{9}{|l|}{ CQC (\%) } \\
\hline Água & 63,78 & 63,89 & 63,99 & 63,02 & 64,07 & 64,15 & 1,9686 & NS \\
\hline Proteína & 60,79 & 61,53 & 62,81 & 59,69 & 61,59 & 62,16 & 5,459 & NS \\
\hline Gordura & 30,16 & 29,87 & 30,09 & 32,20 & 30,05 & 29,62 & 11,350 & NS \\
\hline Cinzas & 11,26 & 11,22 & 11,29 & 10,98 & 11,28 & 11,60 & 8,881 & NS \\
\hline \multicolumn{9}{|l|}{ Taxa de deposição (g/dia) } \\
\hline Proteína & 1,15 & 1,14 & 1,13 & 1,19 & 1,13 & 1,11 & 8,709 & NS \\
\hline Gordura & 3,03 & 3,03 & 3,04 & 2,99 & 3,04 & 3,04 & 2,110 & NS \\
\hline $\begin{array}{l}\text { Energia retida na carcaça } \\
(\mathrm{kcal} / \mathrm{g})\end{array}$ & 34,83 & 34,87 & 34,89 & 34,77 & 34,88 & 34,82 & 0,533 & NS \\
\hline
\end{tabular}

\footnotetext{
${ }^{1}$ Análise de regressão; NS - não significativo.
} 
Tabela 4. Valores médios do balanço de nitrogênio $(\mathrm{BN})$ e do coeficiente de metabolizabilidade do nitrogênio (CM) de codornas de corte no período de 28 a 32 dias de idade em função da porcentagem de inclusão de treonina digestível

\begin{tabular}{lcccccccc}
\hline Variável & \multicolumn{9}{c}{ Treonina digestível (\%) } & CV & Efeito $^{1}$ \\
\cline { 2 - 7 } & 0,93 & 1,00 & 1,07 & 1,14 & 1,21 & 1,28 & & \\
\hline BN (g/dia) & 3,13 & 2,79 & 3,37 & 3,01 & 2,81 & 2,90 & 6,510 & NS \\
CM (\%) & 68,39 & 63,50 & 69,18 & 64,79 & 65,60 & 64,63 & 4,783 & NS \\
\hline
\end{tabular}

${ }^{1}$ Análise de regressão; NS - não significativo.

Dozier et al. (2001), ao trabalharem com dieta contendo $18 \%$ de proteína bruta e $3.200 \mathrm{kcal}$ $\mathrm{EM} / \mathrm{kg}$ e duas porcentagens de treonina total $(0,52$ e $0,74 \%)$ para frangos de corte machos e fêmeas de 42 a 54 dias de idade, verificaram melhor retenção de nitrogênio e energia em frangos machos alimentados com a porcentagem mais alta desse aminoácido. De acordo com Rutz (2002), a carência de aminoácidos essenciais da dieta induz ao balanço negativo de nitrogênio, isto é, a perda é maior do que o consumo. A proteína para a qual o aminoácido essencial estiver faltando não pode ser sintetizada, e os outros aminoácidos que seriam incorporados na proteína serão metabolizados.

Embora não tenha sido verificado efeito significativo da porcentagem de treonina digestível sobre as variáveis analisadas neste estudo, exceto para consumo de treonina e custo da ração, observa-se que o balanço adequado dos aminoácidos permitiu a utilização deles de forma eficiente, sem promover danos ao desempenho das aves.

Considerando que há discrepância dos dados observados neste experimento com os resultados relatados nas literaturas, recomenda-se a realização de mais pesquisas para avaliação do desempenho e da estimativa dos níveis adequados de treonina digestível para codornas de corte em fase final de crescimento.

\section{CONCLUSÃO}

O melhor nível de treonina digestível avaliado foi suficiente para atender as exigências para máximo crescimento de codornas de corte, no período de 15 a 35 dias de idade. Sugerem-se novos estudos que avaliem níveis de treonina digestível menores que $0,93 \%$.

\section{AGRADECIMENTOS}

À Coordenação de Aperfeiçoamento de Pessoal de Nível Superior (CAPES), pelo suporte financeiro; aos grupos de pesquisa de nutrição de não ruminantes e melhoramento genético animal da Universidade Estadual de Maringá; e a todos que colaboraram direta ou indiretamente para a realização deste trabalho.

\section{REFERÊNCIAS}

ALBINO, L.F.T.; BARRETO, S.L.T. Codornas: criação de codornas para produção de ovos e carne. Viçosa, MG: Aprenda Fácil, 2003. 289p.

ATÊNCIO, A.; ALBINO, L.F.T.; ROSTAGNO, H.S. et al. Exigências de treonina para frangos de corte machos nas fases de 1 a 20, 24 a 35 e 44 a 56 dias de idade. Rev. Bras. Zootec., v.33, p.880893, 2004.

BAYLAN, M.; CANOGULLARI, S.; AYASAN, T. et al. Dietary threonine supplementation for improving growth performance and edible carcass parts in Japanese quails, Coturnix coturnix japonica. Poult. Sci, v.5, p.635-638, 2006.

BELlAVER, C.; FIALHO, E.T.; PROTAS, J.F.S. et al. Radícula de malte na alimentação de suínos em crescimento e terminação. Pesq. Agrop. Bras., v.20, p.969-974, 1985.

BERRES, J.; VIEIRA, S.L.; CONEGLIAN, J.L.B. et al. Respostas de frangos de corte a aumentos graduais na relação entre treonina e lisina. Cien. Rural, v.37, p.510-517, 2007.

CORZO, A.; KIDD, M.T.; DOZIER, W.A. et al. Dietary threonine needs for growth and immunity of broilers raised under different litter conditions. Poult. Sci., v.16, p.574-582, 2007. 
DOZIER, W.A.; MORAN JUNIOR, E.T.; KIDD, E.T. et al. Male and female broiler responses to low and adequate dietary threonine on nitrogen and energy balance. Poult. Sci., v.80, p.926-930, 2001.

FISHER, C. Use of amino acids to improve carcase quality of broilers. Feed Mix, v.2, p.1720, 1994.

FRAGA, A.L.; MOREIRA, I.; FURLAN, A.C. et al. Lysine requirement of starting barrows from two genetic groups fed on low crude protein diets. Braz. Arch. Bio. Tech., v.51, p.49-56, 2008 .

FRAIHA, M. Atualização em nutrição proteica para frangos de corte, 2002. Disponível em: $<$ http://www.lisina.com.br/palestras_detalhes.asp $\mathrm{x}$ ?id=63> Acessado em: 20 nov.2003.

FERNANDEZ, R.S.; AOYAGI, S.; HAN, Y. et al. Limiting order of amino acid in corn and soybean cereal for growth of the chick. Poult. Sci., v.73, p.1887-1896, 1994.

KIDD, M.T.; KERR, B.J. L-threonine for poultry. Poult. Sci, v.5, p.358-367, 1996. (Review)

MÓRI, C.; GARCIA, E.A.; PAVAN, A.C. et al. Desempenho e rendimento de carcaça de quatro grupos genéticos de codornas para produção de carne. Rev. Bras. Zootec., v.34, p.870-876, 2005.

MOURA, A.M.A. Conceito da proteína ideal aplicada na nutrição de aves e suínos. Rev. Elet. Nutri., v.1, p.31-34, 2004.

NOBRE, I.S.; COSTA, F.G.P.; SILVA, L.P.G. et al. Exigência de treonina para codornas na fase de crescimento de 22 a 42 dias. In: REUNIÃO ANUAL DA SOCIEDADE BRASILEIRA DE ZOOTECNIA, 46., 2009, Maringá. Anais... Maringá: Sociedade Brasileira de Zootecnia/ Aptor software [2009] (CD-ROM). (Resumo)

OLIVEIRA, E.G.; ALMEIDA, M.I.M.; MENDES, A.A. et al. Avaliação sensorial de carne de codornas para corte, abatidas aos 35, 56 e 77 dias de idade. Vet. Zootec., v.12, p.61-68, 2005 .
REGINATTO, M.F.; RIBEIRO, A.M.L.; PENZ JUNIOR, A.M. et al. Suplementação de treonina em dietas de frangos de corte, variando a energia e as relações energia:proteína. Rev. Bras. Cienc. Avic., v.2, p.239-247, 2000.

ROSTAGNO, H.S.; ALBINO, L.F.L.; DONZELE, J.L. et al. Tabelas brasileiras para aves e suínos: composição de alimentos $\mathrm{e}$ exigências nutricionais. 2.ed. Viçosa, MG:UFV, Departamento de Zootecnia, 2005. 186p.

RUTZ, F. Metabolismo intermediário. In: MACARI, M.; FURLAN, R.L.; GONZÁLES, E. (Eds.). Fisiologia aviária aplicada a frangos de corte. 2.ed. Jaboticabal: FUNEP/UNESP, 2002. $375 \mathrm{p}$.

SAKOMURA, N.K.; ROSTAGNO, H.S. Métodos de pesquisa em Nutrição para Monogástricos. Jaboticabal: FUNEP, 2007. $283 \mathrm{p}$.

SCHERER, C. Exigência nutricional de energia metabolizável, lisina digestível e metionina+cistina digestível para codornas de corte em fase de crescimento. 2009. 118p. Tese (Doutorado em Zootecnia) - Universidade Estadual de Maringá, Maringá, PR.

SILVA, D.J.; QUEIROZ, A.C.D. Análises de alimentos: métodos químicos e biológicos. 3.ed. Viçosa:UFV, 2004. 235p.

SILVA, R.M.; FURLAN, A.C.; TON, A.P.S. et $a l$. Exigências nutricionais de cálcio e fósforo de codornas de corte em crescimento. Rev. Bras. Zootec., v.38, p.1509-1517, 2009.

SOARES, R.T.R.N.; ALBINO, L.F.T.; ROSTAGNO, H.S. et al. Exigência de treonina para frangos de corte no período de 22 a 42 dias de idade. Rev. Bras. Zootec., v.28, p.127-131, 1999.

SISTEMA de análises estatísticas e genéticas SAEG, versão 5.0. Viçosa, MG, 1997. 150p. (Manual do usuário). 